\title{
ENTRE EL HOMBRE LIBRE Y EL DIOS BUENO. ACERCA DE LA FUNDAMENTACIÓN MORAL DE LA CERTEZA EN LA FILOSOFÍA DE DESCARTES
}

Diana Marcela Pinto Parra ${ }^{1}$

\begin{abstract}
Porque primeramente reconozco que es imposible que alguna vez me engañe, puesto que en todo fraude y engaño se encuentra cierto tipo de imperfección y aunque parezca que poder engañar sea señal de sutileza, 0 de poder, sin embargo, querer engañar atestigua sin duda debilidad o malicia.

Y por consiguiente esto no puede encontrarse en Dios. Y después experimento en mí mismo cierta facultad de juzgar, que sin duda he recibido de Dios, igual que todo lo demás que poseo; y como él no podría querer engañarme, es seguro que me la ha dado de modo que jamás pueda errar mientras la use como es debido.
\end{abstract}

René Descartes.

Meditaciones Metafísicas

A mi Padre.

\section{Resumen}

$\mathrm{E}$ ste artículo realiza un acercamiento a la teoría del conocimiento planteada por Descartes, para dilucidar cómo a la base del argumento racional que hace de Dios el aval del conocimiento, se manifiestan dos aspectos fundamentales: la libertad infinita de Dios, y la libertad que éste le brinda al hombre. Para ello, mostraremos que al decidir no engañar, Dios hace uso de su libertad y se presenta como un ser moralmente perfecto. Así mismo, veremos que Dios otorga al hombre una total libertad epistémica al darle la posibilidad de ir desde sí mismo al conocimiento y de tomar una decisión sobre lo que su entendimiento le presenta. De esta manera, en la teoría cartesiana el conocimiento involucra también un perfil moral, ya que implica elección, y esto le permite al filósofo francés librar a Dios de la responsabilidad de la aparición del error en el conocimiento humano.

\section{Palabras clave}

Verdad, ruta epistemológica, libertad, responsabilidad, Dios creador, bondad de Dios.

\section{Abstract}

This article develops and approach to the Theory of the Knowledge proposed by Descartes, in order to elucidate the way the rational argument that makes God the guarantee of knowledge is supported by two suppositions: the infinity God's liberty and the freedom that God gives to human being. To catch this purpose up it will be showed that God, deciding not to deceive, presents himself as a morally

1. Artículo presentado como Trabajo de Grado, requisito para optar por el título de Profesional en Filosofía de la Universidad Minuto de Dios. Director: Nelson Arango; Jurado: Gloria Díaz. 
perfect being. By the way, it will be made clear that God grants to the human being a total epistemic freedom giving him the possibility to go from himself to the knowledge and making a choice about what his understanding presents to himself. In this way, knowledge in Cartesian theory involves a moral profile too, owing to the fact that it implies a choice. This procedure makes possible that God, in the French philosopher system, had not duties about mistake in human knowledge.

\section{Key words}

Truth, epistemological way, freedom, duty, God the Creator, God's kindness.

\section{Artículo}

Recibido el 22 de febrero de 2009, aprobado el 20 de octubre de 2009

\section{Introducción}

Como es bien sabido, la teoría cartesiana del conocimiento presenta una propuesta para la investigación de la verdad, que parte del entendimiento del sujeto y de la duda como impulsadora de la búsqueda de la certeza. Esto la distancia de la indagación que tradicionalmente se llevaba a cabo, y que hallaba su fundamento en los incuestionables argumentos de autoridad y el empirismo aristotélico. Igualmente, aunque otorga un lugar fundamental a Dios dentro de él, al situarlo como aval de la certeza epistemológica humana, Descartes es enfático en su intención de no tratar asuntos referentes a verdades de fe en su proyecto.

Ante tal planteamiento podría afirmarse que, aunque las características del método y lo que denominamos la ruta epistemológica cartesiana, permiten considerar que el tema de Dios es abordado como una verdad racional al interior de esta teoría, el contenido de su idea, así como sus atributos, terminan anclando esta noción a las creencias religiosas tradicionales. Así mismo, a través de la investigación epistémica se hace visible, tras el infinito poder de Dios, su ilimitada libertad, que consiste en que pese a estar facultado para hacer cualquier cosa, incluso engañar al hombre en los hallazgos de su razón, decide no hacerlo, y es aquí donde se destaca su rasgo de ser 'soberanamente bueno.' Por otro lado, Dios también otorga al hombre la oportunidad de conocer la verdad al darle la libertad, en primer lugar, de buscarla, y en segundo lugar, de decidir suspender el juicio, asentir o negar, según sea el caso, a lo que su entendimiento le muestra. Así, se crea una doble relación del hombre respecto a Dios: de dependencia, dada su condición natural de creatura, pero a la vez de libertad epistémica, que no obstante, adquiere precisamente gracias a su creador.

Abordar cómo se da esta doble relación, de libertad en Dios y en el hombre, es nuestra intención al acercarnos a las Meditaciones Metafísicas. A partir de éstas, identificaremos algunos argumentos que permiten hablar de la posibilidad del conocimiento de Dios como verdad epistemológica, dentro de la teoría cartesiana del conocimiento, lo que ayuda a comprender que de esta forma el sujeto toma una ruta de indagación que lo hace libre de ir desde sí mismo hacia la certeza, al distanciarse de los asuntos de fe, la tradición y los argumentos de autoridad. En un segundo momento, analizaremos cómo la hipótesis del Dios engañador se convierte en parte fundamental de la investigación racional, al hacer tambalear la veracidad de las, hasta ese momento, incuestionables verdades matemáticas. Allí encontramos a un sujeto que se siente libre de dudar, y de suspender el juicio, ante la imposibilidad de encontrar evidencias confiables.

En tercer lugar, presentaremos cómo el cogito se convierte en la posesión de conciencia, que además de sus referencias epistémicas, en el plano moral responsabiliza totalmente al sujeto del buen uso de sus facultades racionales, y de la búsqueda del conocimiento. Posteriormente, a través de la idea de Dios veremos que la noción de infinito se vuelve la referencia que abre las 
posibilidades de conocimiento al hombre, liberándolo epistemológicamente, aunque también deja al descubierto los límites de su razón. Para finalizar, identificamos dos características del Dios cartesiano, su condición de creador del sujeto y su bondad, que son fundamentales para que sea imprescindible su presencia en esta teoría racionalista. Nuestra hipótesis es que la soberana bondad de Dios aparece gracias al ejercicio de su libertad, cuando decide no engañar al hombre, este es el punto culminante de la teoría cartesiana del conocimiento, pues la bondad divina garantiza la certeza y exime a Dios de la responsabilidad de la aparición del error epistémico, transfiriéndosela por completo al hombre.

\section{La posibilidad del conocimiento de Dios como verdad epistemológica}

Para iniciar nuestra investigación hay que partir de la consideración de Dios en la teoría cartesiana del conocimiento, para despejar algunas dudas que surgen respecto a la presencia de tal Ser al interior de ella y comprender que lo que prima en la investigación cartesiana es la búsqueda de la verdad que tiene como punto de partida al sujeto, ruta epistemológica que le otorga libertad de indagación y lo distancia de la tradición. La presencia de Dios en la teoría cartesiana del conocimiento, suscita varias preguntas: ies la demostración de la existencia de Dios el motivo principal de Las Meditaciones?, ¿cómo se puede abordar un tema de esta naturaleza, dejando de lado asuntos de fe, distanciándose de la tradición, y concentrándose únicamente en los hallazgos de la razón? y, ¿es Descartes un escolástico más, al comprometerse con un asunto religioso dentro de una teoría filosófica?

Para intentar dilucidar estas cuestiones y para comprender un poco más a fondo la conjunción de elementos como la libertad del hombre, la búsqueda de la certeza en el conocimiento, y Dios como parte de esta búsqueda en el proyecto cartesiano, en primera instancia hay que centrar la mirada en el mensaje que Descartes dirige a los decanos de la Facultad de Teología de París. Allí manifiesta que la existencia de Dios es una verdad absoluta, incuestionable desde la fe, a la que también se puede llegar desde el entendimiento del hombre, el cual es capaz de brindar razones suficientes para la comprobación de la misma. En este orden de ideas, la existencia de Dios puede ser tomada como una verdad en sentido religioso, o en sentido epistemológico.

Sin embargo, esto no significa que Descartes asuma una especie de 'doctrina de la doble verdad', lo que sucede es que siendo Dios una verdad absoluta, ésta puede considerarse en los dos sentidos ya enunciados, sin que estas posturas tengan que reñir entre sí o anularse mutuamente. Es más, para Descartes la verdad racional de la existencia de Dios puede contribuir a afirmar las creencias religiosas.

Respecto a la primera opción mencionada, cuando se está ante una verdad revelada su lugar propio es el de la creencia y es natural que una verdad así exceda el entendimiento humano, pues no pertenece al campo de la razón. Descartes es reiterativo en esta postura en todos sus escritos, en los Principios de la Filosofía, confirma de manera contundente:

Debemos creer todo lo que Dios ha revelado, aunque exceda nuestra capacidad. Así, si Dios nos revelara algo sobre sí mismo 0 sobre otras cosas que excediera nuestra capacidad natural de inteligencia, como ocurre con los misterios de la Encarnación y de la Trinidad, no rehusaremos el creerlo, aunque no lo entendamos claramente. Y en modo alguno nos extrañaremos que haya muchas cosas que excedan nuestra capacidad, tanto en su naturaleza inmensa como en las cosas creadas por él $\left.\right|^{2}$.

De esta manera, se puede notar que al transitar la ruta de fe nos encontraríamos inmediatamente con la inconmensurabilidad racional de Dios. 
Ahora bien, cuando se hace alusión a la verdad desde la razón, ésta en Descartes toma un cariz diferente, seconvierteenunasunto deindagación del entendimiento, de cuestionamiento de toda creencia, de juzgar, lo que dista de la postura de fe. Dado que el filósofo francés quiere emprender una ruta racional para hallar la certeza absoluta en el conocimiento, necesita entonces llevar a cabo una introspección de su espíritu para llegar al conocimiento de la verdad; por ello, se vale de un método que le permita hacer uso de la intuición intelectual de manera correcta, para no caer en el error y poder avanzar en su búsqueda de certeza ${ }^{3}$.

La investigación racional se convierte en el espacio adecuado para establecer la veracidad de toda creencia que resista el filtro de la duda, como es el caso de la existencia de Dios, pues al someterla a juicio por este medio y hallarla verdadera, las evidencias encontradas, es decir las razones que apoyan su veracidad, la harán irrefutable ante cualquier intento de cuestionamiento posterior.

En la carta dirigida a los teólogos mencionada arriba, Descartes sugiere que la demostración de la existencia de Dios en su teoría puede ofrecer razones desde la filosofía, que con la sola ayuda de la razón natural, permitan establecer fundamentos indudables capaces de persuadir hasta a los infieles más tercos, dado que ellos, al no poseer la fe, necesitan explicaciones racionales para convencerse de las verdades más evidentes. Por eso "no se podría hacer nada más útil en filosofía que investigar una vez afanosamente y con cuidado las mejores y más solidas (razones) y disponerlas en un orden tan claro y exacto que conste, sin embargo, a todo el mundo que son verdaderas demostraciones." ${ }^{14} \mathrm{De}$ esta manera, Descartes puede tomar distancia sobre cuestiones de fe y toma partido por una indagación epistémica.

En este punto se dilucida cómo la senda escogida por Descartes en su investigación, lo distancia con la manera de proceder de la escolástica, que según él, se encuentra firmemente aferrada a la dialéctica y a los argumentos de autoridad. Respecto de esta manera de proceder para llegar a la verdad, Descartes tenía serias reservas; así lo consigna en las Reglas para la Dirección del Espíritu:

Algunas personas se extrañarán quizá de que buscando aquí los medios de hacernos más aptos para deducir unas verdades de otras omitamos todos los preceptos por los cuales los dialécticos creen deducir la verdad humana, prescribiendo ciertas formas de razonamiento tan necesariamente concluyentes, que aunque a la razón que confía en ellas no le importe /considerar atenta y evidentemente la inferencia misma, pueda sin embargo, a veces, sólo por la fuerza de la forma establecer conclusiones ciertas. ${ }^{5}$

A partir de lo anterior salen a relucir dos aspectos que considerar. El primero es que para Descartes la filosofía no es un simple instrumento de la teología, utilizado para defensa de verdades dadas, sino que es el estudio del perfecto conocimiento de lo que el hombre puede saber; y para adquirir tal conocimiento, éste debe ser deducido desde las primeras causas, es decir, desde los principios, los cuales se deben hallar a partir del entendimiento humano. Por consiguiente, se hace visible que aunque Descartes aborda el tema de Dios en su teoría, no es un escolástico más.

3. Descartes entiende por método: "reglas ciertas y fáciles, cuya/ rigurosa observación impide que jamás se suponga verdadero lo falso y hace que la inteligencia, sin gasto inútil de esfuerzos sino aumentando siempre la ciencia, llegue al verdadero conocimiento de todo lo que es capaz." DESCARTES, René, "Reglas para la dirección del espíritu", en: Obras Escogidas, Trad. Ezequiel de Olaso, Charcas, Buenos Aires, 1980, Regla IV, p. 45, (ATX, 372).

4. DESCARTES, René, "Meditaciones Metafísicas", en: Obras Escogidas, Trad: Ezequiel de Olaso, Charcas, Buenos Aires, 1980, Carta a los Señores Decanos de la Sagrada Facultad de Teología de Paris, p. 203. (AT IX, 6) Hay que aclarar que la utilidad a la que se refiere Descartes, no debe tomarse como si la filosofía fuera un instrumento de la teología al estilo medieval, sino que la filosofía como búsqueda del conocimiento perfecto, a través de sus razones, puede ayudar a una causa religiosa, la cual tiene como verdad de fe la existencia de Dios.

5. DESCARTES, René, Óp. cit., "Reglas para la dirección del espíritu", Regla X, p. 75. (AT, X 105-106). 
Aunque la demostración de la existencia de Dios desde la razón no es lo que motiva la búsqueda cartesiana de la verdad, sino la búsqueda de la certeza epistemológica, aquella aparece allí, y podría llegar a ser bastante útil a una causa religiosa como es convencer a los ateos, pues las razones que apoyan esa verdad son aptas para ser entendidas por todo sujeto racional, independientemente de creencias religiosas. Descartes había afirmado en el Discurso del Método que "el buen sentido es la mejor cosa repartida en el mundo: (...) el poder de juzgar bien y distinguir lo verdadero de lo falso, que es propiamente lo que se llama buen sentido o razón, es naturalmente igual en todos los hombres."

La verdad se convierte así en un asunto secular, pues aunque sea la existencia de Dios el objeto de demostración en determinado momento de la indagación epistémica, es gracias a la vía racional que puede ser posible conocerla, y esto es lo que prima en Descartes. Si bien es cierto que en la Carta a los Decanos el tema de Dios aparece como asunto central de Las Meditaciones, y el título de éstas lo ratifica ${ }^{7}$, la búsqueda de un conocimiento desde la luz natural y ya no desdela revelación y lafe, permite a Descartes situarse en un ámbito racional, tomando una ruta distinta a la que le marcan sus creencias religiosas. En este sentido, lo central de la propuesta epistemológica cartesiana es llegar a la certeza en el conocimiento, y Dios es parte fundamental en este proceso, pues aparece en esta búsqueda para respaldar la verdad.
Por las características de la indagación racional ejercida por Descartes en pro de la verdad, señala Serrano:

Descartes forja una nueva mentalidad que será definitiva para el hombre moderno, pues lo conmina a pensar por sí mismo y cerciorarse a solas de toda verdad, en desmedro de la costumbre, la autoridad, la tradición y el consenso; le demuestra, como comienzo absoluto de su saber, el saber de sí mismo, el cual le dará la impronta de subjetivismo a la mentalidad moderna; elimina el argumento entretejido de los escolásticos como instrumento de conocimiento, relegándolo a mera retórica 0 máquina de combate y proselitismo, y como su contrapartida nos deja una teoría del conocimiento que impone al saber y a la ciencia un orden lineal de descubrimiento a descubrimiento, empezando siempre desde el fundamento absoluto. ${ }^{8}$

Aunque es claro que hallar la certeza en el conocimiento a través de la indagación epistémica es la prioridad de Descartes, y no tratar temas de fe, hemos visto a partir de la consideración de la presencia de Dios en este terreno racional que, aunque el hombre por su condición de ser finito no tiene acceso al conocimiento de la totalidad de lo que es Dios, sin embargo, está facultado para conocer de manera cierta su existencia ${ }^{9}$. De otro lado, cuando el hombre decide buscar por sí mismo el conocimiento perfecto, abandona cualquier argumento de autoridad y se hace libre de acceder a la verdad epistemológica, que puede ser conocida por todo sujeto racional. De esta manera, la libertad se manifiesta como una condición fundamental de la investigación cartesiana.

6. DESCARTES, René, "Discurso del Método", en: Obras Escogidas, Trad: Ezequiel de Olaso, Charcas, Buenos Aires, 1980, Primera Parte, pp. 135-136 (AT VI, 2-3). Descartes en algunos pasajes de sus textos manifiesta que no todos los espíritus son aptos para entender las verdades racionales; el motivo de ello no es que unos hombres sean mejor dotados de facultades para el conocimiento que otros. Sucede que: "el hombre entró ignorante en el mundo, y al no ser apoyado su conocimiento de la primera edad más que sobre la debilidad de los sentidos y la autoridad de los preceptores, es casi imposible que su imaginación no se encuentre llena de una infinidad de falsos pensamientos antes que la razón pueda dirigirla." DESCARTES, René, "Investigación de la verdad por la luz natural', en: Meditaciones Metafísicas y otros textos, Trad: E. López y M. Graña, Gredos, Madrid, 1987, p. 89.

7. El mismo título que Descartes colocó a las meditaciones: Meditaciones sobre filosofía primera en las cuales se demuestran la existencia de Dios y la distinción real entre el alma y el cuerpo del hombre, hace un énfasis en el tema de Dios, pero al adentrarse en el texto se encuentra una búsqueda epistemológica en la cual Dios es fundamental, pero que finalmente, parte del entendimiento del hombre que quiere conocer la verdad.

8. SERRANO, Gonzalo, "QQué nos importa Descartes todavía?" en: Memorias del seminario en conmemoración de los 400 años del nacimiento de René Descartes, Academia Colombiana de Ciencias Exactas, Físicas y Naturales, Bogotá, 1997, p. 8.

9. Descartes afirma en su respuesta a las Primeras Objeciones: "Por lo que a mí toca, siempre que he dicho que Dios podía ser conocido clara y distintamente, he querido referirme a dicho conocimiento finito, y acomodado a la escasa capacidad de nuestro espíritu." DESCARTES, René, Meditaciones metafísicas con objeciones y respuestas, Trad: Vidal Peña, Alfaguara, 1977, Respuesta a las Primeras Objeciones, p. 96. 


\section{La incertidumbre respecto a las cosas simples y la posibilidad del hombre de suspender el juicio}

Emprender una ruta epistemológica hacia la verdad, que como hemos visto, pretende hallar la absoluta certeza en el conocimiento, exige al sujeto la disposición de no dar crédito a lo que no aparezca en el entendimiento con suficiente evidencia, o que presente asomo de duda. Por ello, la duda se convierte en un factor primordial en la investigación cartesiana, al permitir separar lo cierto de lo que no lo es, ya que si se duda de algo, aquello no es la verdad, porque la verdad no admite duda. Debemos mencionar en este punto que a pesar de las críticas hechas a la radicalidad de la duda cartesiana, ésta es un elemento imprescindible ante la necesidad de encontrar fundamentos confiables en los cuales establecer un conocimiento cierto.

Si como vimos, el hombre es libre de usar su facultad racional para encontrar el conocimiento verdadero, también lo es para hacer cuanto esté a su alcance para conseguirlo. Por ello, la duda no es una exageración fruto de un presuntuoso deseo de originalidad, sino que es una estrategia filosófica que permite poner en tela de juicio cualquier creencia, por evidente que pueda parecer, para someterla a la indagación racional; sólo así se puede llegar a la certeza absoluta. De esta manera, hasta las nociones simples, consideradas como las verdades más evidentes, pueden ser sometidas al examen racional sin incurrir en el absurdo.

En este orden de ideas, la desconfianza respecto a la experiencia sensorial de verdad lleva a Descartes a erradicar toda creencia anterior fundada en los datos de los sentidos, pues esta vía puede conducir a caer en el error. De igual manera, posteriormente, el argumento del sueño traslada el problema de la verdad de la falla de los sentidos hasta la existencia misma de las cosas. A través de este argumento también son puestas en tela de juicio las verdades matemáticas, que salen bien libradas, pues tanto en el sueño como en la vigilia dos y tres siempre serán cinco; ${ }^{10}$ entonces, ¿cómo se podría dudar de algo tan evidente? Sin embargo, cuando Descartes enuncia: "no parece posible que verdades tan claras puedan ser sospechosas de falsedad o incertidumbre alguna"," al referirse a lo simple de la aritmética y la geometría, deja aún espacio de duda acerca de ellas.

La primeraalusión a Diosen Las Meditaciones, aparece en este momento de confusión respecto a las nociones matemáticas, para radicalizar la duda en torno a una verdad que nadie osaría cuestionar. Dicha alusión hace referencia a la opinión que tiene Descartes sobre la existencia de un Dios todopoderoso y creador de su ser, ${ }^{12}$ que tal vez querría engañarlo haciéndole creer que existen las cosas extensas, desde su propio cuerpo, hasta todo cuanto lo rodea, siendo aquello tan sólo falsedad. Y es tanto el poder que ostenta ese Dios, que incluso puede hacer que se equivoque en lo más evidente, como por ejemplo, en que la suma de dos y tres es cinco. ${ }^{13}$ Así, el alcance de aquel Ser lo sumerge aún más en el escepticismo, haciendo tambalear lo que parecía más cierto: las verdades matemáticas.

La opinión de ese Dios todopoderoso y creador, que por su gran poder podría engañar al hombre en lo que se muestra como más evidente, no será abandonada

10. DESCARTES, René, Óp. cit., Meditaciones Metafísicas, Primera Meditación, p. 219, (AT IX, 16). Las verdades matemáticas tienen validez por encima de la existencia misma, pues, por ejemplo, no se necesita que exista un triángulo para que sea perfectamente cierto que está formado por tres lados.

11. Ibíd., Primera Meditación, p. 219, (ATIX, 16).

12. Ibíd., Primera Meditación, p. 219, (AT IX 16).

13. Cfr., Primera Meditación, p. 219, (AT IX 16). Inmediatamente después de enunciar la posibilidad de que Dios pudiera engañarlo respecto a las verdades matemáticas, Descartes hace una pequeña alusión a la bondad de Dios, pues por ese atributo tal vez no engañaría al hombre de ese modo: "Pero quizá no ha querido que fuese engañado de esa manera, pues es soberanamente bueno." Ibíd., Primera Meditación, p. 220, (AT IX 16). No abordamos este tema aquí pues Descartes lo deja de lado, y sólo lo retoma hasta la tercera meditación. 
por Descartes hasta ser examinada por el entendimiento, como todas las demás nociones en torno a las cuales haya duda y que sea necesario abordar para llegar a la certeza. Por ello, en el primer apartado mencionamos que el tema de Dios es abordado como cualquier otra creencia que aparezca ante la razón y que requiera la búsqueda de evidencias confiables.

Ahora bien, Dios se convierte en un factor imprescindible de esta teoría, al ser una noción simple al igual que las verdades matemáticas, pero a diferencia de éstas, hace referencia a un Ser con voluntad, que puede hacer cualquier cosa, incluso engañar al sujeto. Este rasgo divino es fundamental, como veremos más adelante, pues la voluntad infinita de Dios desplegada hacia su creatura, crea una dependencia del hombre hacia él, aunque también, esa voluntad le otorga al hombre la libertad de llegar desde sí mismo al conocimiento perfecto. Por esto, la noción de Dios, y en ella su libertad, atraviesa toda la investigación cartesiana y termina convirtiéndose en la piedra angular de su teoría del conocimiento.

Una vez que aparece la noción de un Ser que crea al sujeto, el cual es todopoderoso, surgen otros interrogantes: si ese creador es tan poderoso, ¿cómo es posible que el sujeto, su creatura, se equivoque en sus juicios?, ¿será acaso que dicho Ser creó al hombre de tal manera que fuera su naturaleza caer en el error?, más aún, ¿será que el creador del sujeto no es tan poderoso, al crear un ser imperfecto? Descartes reconoce que por lo menos algunas veces, Dios permite que se equivoque. Ante tal situación enuncia:

(...) es seguro que, puesto que errar y equivocarse/ es una especie de imperfección, cuanto menos poderoso sea el autor a que atribuyan mi origen, tanto más probable será que yo sea tan imperfecto que me engañe siempre. Razones a las que no tengo nada que contestar, aunque me veo obligado a reconocer que de todas las opiniones que en otro tiempo había creído verdaderas, no hay ni siquiera una de las que no pueda ahora dudar, no por irreflexión o ligereza alguna, sino por razones muy fuertes y maduramente consideradas: de modo que es necesario que detenga y suspenda desde ahora mi juicio sobre estos pensamientos y que no les preste más crédito que el que prestaría a cosas que me parecieran evidentemente falsas, si deseo encontrar algo permanente y seguro en las ciencias. ${ }^{14}$

El no poder responder cuestionamiento alguno, hace que lo más prudente sea suspender el juicio acerca de Dios y del error, por no ser todavía la ocasión para abordarlo. Y es que no hay que olvidar que la pretensión cartesiana es edificar el conocimiento desde bases sólidas, desde principios indudables que todavía no tiene.

Lo anterior, revela que el sujeto que indaga la verdad es un ser libre de conducir su facultad de conocer, pues aunque exista un ser todopoderoso por el cual ha sido creado y aunque el alcance de tal poder sea ilimitado, sin embargo, la decisión de suspender el juicio e incluso abandonar su investigación cuando no está seguro de avanzar en la dirección correcta hacia la certeza, está únicamente en sus manos. Esto supone la responsabilidad del sujeto en la construcción de su conocimiento, pues asentir o negar, sin tener el pleno convencimiento de esa decisión, puede llevarlo inevitablemente al error y la falsedad.

Sin embargo, podemos afirmar también que la hipótesis del Dios engañador, la cual hace tambalear las verdades matemáticas, muestra la dependencia del hombre respecto al creador de todas las cosas cuando quiere llegar a la certeza en el conocimiento. La existencia de un Ser que todo lo puede, por ende, con una libertad ilimitada, que además, crea al hombre (el cual por su condición de creatura es limitado), tiene tal potestad sobre él que puede llegar hasta su razón, engañándolo incluso en lo que se presenta a su entendimiento como más evidente.

De igual manera, que la presencia de Dios en esta indagación racional sea capaz de 
poner en duda verdades tan simples como las matemáticas, demuestra que la noción de Dios, y Dios mismo, están por encima de dichas verdades. Es más, Dios está por encima de ellas porque es quien las crea; así lo expone Descartes a Mersenne en una de sus cartas:

Pero no dejaría de tocar en una física muchas cuestiones metafísicas y particularmente ésta: que las verdades matemáticas, que usted llama eternas, han sido establecidas por Dios y dependen enteramente de él, lo mismo que todo el resto de las criaturas. ${ }^{15}$

Vemos entonces que, al poseer Dios características como ser creador del sujeto pensante y de las verdades matemáticas, además, al tener un poder ilimitado, se va convirtiendo en un elemento imprescindible en la teoría cartesiana del conocimiento. Este asunto necesita ser clarificado, pues hasta lo que se presenta como más evidente al entendimiento del hombre puede ser puesto en duda a causa de ese Ser externo, que tal vez influye en los hallazgos de su razón. Decimos que Dios es un agente externo a la consciencia del sujeto, porque además de estar presente allí como una idea innata, que permite encontrar la verdad y servir de garantía del conocimiento, también es un Ser que existe de manera objetiva y es creador del hombre. Sin embargo, más adelante veremos que Dios termina por fundirse con la consciencia del sujeto, al ser su idea la verdad absoluta que engloba todo lo claro y distinto que el hombre puede hallar en el interior de su entendimiento.

\section{El descubrimiento de la conciencia del hombre y de su responsabilidad en la adquisición de la certeza}

Cuando la hipótesis del Dios engañador ha fomentando el escepticismo hasta el extremo de poner en duda la certeza de las verdades matemáticas, y el genio maligno cuestiona la existencia misma de las cosas, ${ }^{16}$ Descartes toma la radical decisión de suponer la falsedad de todo cuanto se presenta ante él y está decidido a no cambiar de parecer hasta encontrar algo cierto, es decir, debidamente respaldado por evidencias racionales de las cuales sea imposible dudar. Sin embargo, hace la salvedad de que si definitivamente fuera imposible encontrar evidencia sobre alguna cosa, en ese caso lo mejor sería suspender el juicio y aceptar que todo es una ilusión, antes que dar por cierto algo que albergase duda.

Dado que en este momento no hay algo que no sea considerado falsedad, se revelan dos probabilidades: la primera es que definitivamente nada exista y la segunda, que haya un engañador muy poderoso de cuyos ardides sea imposible salir. ${ }^{17}$ El escepticismo radical por fin se detiene, cuando Descartes ante un supuesto ataque del engañador afirma:

No hay pues, ninguna duda de que existo si me engaña, y engáñeme cuanto quiera, jamás podrá hacer que yo no sea nada en tanto que piense ser alguna cosa. De modo que después de haber pensado bien, y de haber examinado cuidadosamente todo, hay que concluir y tener por establecido que esta proposición: yo soy, yo existo, es necesariamente verdadera siempre que la pronuncio o la concibo en mi espíritu. ${ }^{18}$

Así, se presenta al entendimiento la evidencia que respalda la primera certeza: el cogito. Esta certeza de la existencia se convierte en el punto arquimédico que Descartes buscaba para emprender una ruta epistemológica hacia la verdad. Luego de saber de su existencia, el cogito lleva a 
Descartes a querer conocer qué es ély le hace descubrir posteriormente lo que considera su único atributo:"yo no soy, pues, hablando con precisión, más que una cosa que piensa, es decir, un espíritu, un entendimiento o una razón, que son términos cuyo significado antes me era desconocido."19

A partir de lo anterior podemos afirmar que dicho cogito no es tan sólo un acto del entendimiento, sino una posesión de conciencia, ya que el sujeto que piensa sabe que piensa y ello constituye su yo, el sujeto es entonces, un yo pensante. ${ }^{20}$ De esta manera, Descartes pone su ser totalmente en el pensar, en su razón, prescindiendo de toda dependencia del cuerpo. La evidencia racional de la existencia hace visible que la verdad debe ser buscada más allá de las construcciones lógicas de la filosofía escolástica, la certeza de la existencia es una noción simple que está en el entendimiento y que se halla, si el sujeto se toma el trabajo de realizar de forma rigurosa una inspección del espíritu. Esta noción de la existencia es como un sello que posee el sujeto, que es puesto por su creador para facultarlo epistemológicamente.

Ahora bien, el descubrimiento de la condición de ser pensante y de la existencia, que Descartes encuentra como algo verdadero, le hace darse cuenta de que en ese conocimiento se encuentra una percepción clara y distinta:

En este primer conocimiento no se encuentra más que una percepción clara y distinta de lo que conozco; la cual en verdad no sería suficiente para asegurarme de que es verdadera si pudiese ocurrir alguna vez que fuese falsa una cosa que fuese concebida por mí tan clara y distintamente: $y$, por consiguiente, me parece que ya puedo establecer por regla general que todas las cosas que concebimos muy clara y distintamente son verdaderas. ${ }^{21}$

En este punto vemos cómo a partir del descubrimiento de la condición de 'ser pensante', emerge el criterio de claridad y distinción, ${ }^{22}$ el cual se vuelve fundamental en la búsqueda de la verdad al permitir el examen cuidadoso de las ideas que se muestran al entendimiento, para establecer la veracidad o falsedad de cada una de ellas, y asentir o negar, según el caso. Esto demuestra que el sujeto en primera instancia, percibe en el entendimiento, para luego asentir con la voluntad, lo cual hace patente la posibilidad de elección sobre los hallazgos de su razón y por ende, de su libre albedrío:

Más aunque acaso haya muchos que, al considerar la preordenación divina, no puedan entender cómo se concilia con nuestra libertad, sin embargo, no hay nadie que, observándose solamente a sí mismo, deje de sentir que la voluntad y la libertad son una sola cosa, 0, más bien, que no hay diferencia entre lo voluntario y lo libre. ${ }^{23}$

De este modo, el criterio de verdad surge del yo que piensa, de un ser con consciencia tanto para conocer, como para asentir o negar, podemos afirmar que el sujeto posee una consciencia deliberativa. El conocimiento es fruto no solamente de un acto de percepción, sino que éste implica la toma de una decisión, con lo cual lo epistémico involucra también un plano moral. En este sentido, el yo pone el criterio de verdad, que es el medio que posee el sujeto

19. Ibíd., p. 226.

20. Respecto al cogito, Descartes afirma en su respuesta a las Quintas Objeciones: "Pues el conocimiento de los primeros principios y axiomas no suele ser llamado ciencia por los dialécticos. Más cuando percibimos que somos cosas pensantes, ésa es una noción primera, no sacada de silogismo alguno; y cuando alguien dice, pienso, luego soy o existo, no infiere su existencia del pensamiento como si fuese la conclusión de un silogismo, sino como algo notorio por sí mismo, contemplado por simple inspección del espíritu". DESCARTES, René, Óp. cit. Meditaciones Metafísicas con Objeciones y Respuestas, Respuestas a las Quintas objeciones, p. 115.

21. DESCARTES, René, Óp. cit., Meditaciones Metafísicas, Tercera Meditación, pp. 233-234, (AT IX, 27).

22. Descartes posteriormente, en los Principios de la Filosofía, define ideas claras y distintas de la siguiente manera: "Llamo idea clara a la que está presente y manifiesta para una mente atenta, de la misma manera que decimos que vemos claramente aquello que miramos, y que está presente ante nuestros ojos afectándolos con suficiente intensidad. Y llamo distinta a la que, además de ser clara, es de tal modo precisa y separada de todas las demás, que no contiene más que lo que es claro." DESCARTES, R., LEIBNIZ, G., Óp. cit., Sobre los Principios de la Filosofía, p. 50.

23. DESCARTES, René, Óp. cit., Meditaciones Metafísicas con Objeciones y Respuestas, Respuestas a las Terceras Objeciones, p. 155. 
para obtener el conocimiento y que sirve de base para tomar la decisión de afirmar o no, las percepciones del entendimiento; ello le otorga responsabilidad al sujeto en la consecución de la certeza. Así se hace patente la búsqueda estrictamente racional que perseguía Descartes, liberada de cualquier percepción sensible, prejuicios y creencias anteriores.

Luego de la erradicación de cualquier creencia gracias a la duda, el terreno epistemológico queda apto para empezar a edificar los nuevos cimientos del conocimiento. Dichos cimientos están ahora fundados en el propio entendimiento del sujeto, el cual a través del cogito como punto arquimédico, puede alcanzar el conocimiento. Aquí, gracias al criterio de claridad y distinción, el sujeto tiene la posibilidad de encontrar desde sí mismo la verdad.

\section{La idea de Dios como posibilitadora del conocimiento del sujeto}

Aunque el criterio de verdad basado en la claridad y distinción, es la más confiable posesión del sujeto para encontrar el conocimiento, la posibilidad de que un agente externo pueda influir en su entendimiento obliga a Descartes a meditar sobre ese Ser todopoderoso por el cual son puestas en tela de juicio, la certeza, a la cual puede llegar como sujeto pensante, y las verdades matemáticas, las que se tenían como lo más evidente desde el inicio de la investigación.

Recordemos que Descartes había propuesto la existencia de un Dios todopoderoso, cuyo alcance podría hacer que incluso el conocimiento de las verdades matemáticas fuera dudoso. Para despejar definitivamente esta sombra de incertidumbre, que frena el camino hacia la certeza, se hace necesario investigar dos aspectos: si tal Dios efectivamente existe y si es engañador. Con ello, también es puesta a consideración la existencia de Dios, lo que demuestra que ninguna noción simple escapa a la necesidad de evidencia racional, y que el conocimiento requiere ser edificado desde cimientos sólidos y en un estricto orden.

De manera que, tras el análisis de las clases de ideas y el origen de las mismas, Descartes se encuentra con una fundamental, con la idea de Dios:

(...), aquella mediante la cual concibo un Dios soberano, eterno, infinito, inmutable, omnisciente, todopoderoso, y creador universal de todas las cosas que están fuera de él; aquella, digo, por cierto contiene en sí misma más realidad objetiva que aquellas que me representan las sustancias finitas. ${ }^{24}$

Posteriormente, a partir de la idea de Dios surge el primer argumento en favor de demostrar la existencia de éste Ser. En dicho argumento se presenta la idea de Dios como poseedora de más realidad objetiva que cualquier otra, al representar una sustancia con unas características de perfección, idea que se encuentra alojada en el sujeto pensante de manera innata. Pero a pesar de ser concebida por el sujeto, éste no puede ser su causa, puesto que lo menos perfecto no puede ser causa de lo más perfecto, por lo cual, la causa de la idea de Dios definitivamente es otro ser diferente al hombre, el cual debió colocarla en su entendimiento. Así mismo, Descartes argumenta que la idea de una sustancia infinita, es decir Dios, que contiene atributos tan excelsos como la independencia y la omnipotencia, jamás tendría origen en el sujeto, pues su condición de sustancia limitada lo impediría.

Pero podría pensarse que quizá la finitud del hombre da lugar a la idea de infinitud, que su condición carente lo lleva a concebir lo que no posee. Ante esta situación, Descartes plantea que la idea de infinitud en el sujeto es anterior a la de finitud, pues aquella es la que permite al sujeto darse cuenta que le falta algo. Entonces la infinitud posibilita al hombre compararse con una cosa superior, para así poder conocer los defectos de su naturaleza. Con base en los anteriores 
argumentos se puede afirmar que Dios existe y es la causa de su idea, la cual está alojada en el entendimiento del sujeto de manera innata. Es por medio de ella que dicho sujeto puede llegar a conocer a tal Ser.

La idea de Dios se establece así, como la representación de un Ser infinitamente perfecto, como la poseedora de la mayor realidad objetiva, claridad y distinción, por tanto la más verdadera; lo cual es un rasgo distintivo de dicha idea. Pero lo más significativo tras esta noción, es que ella engloba todo lo claro y distinto que puede albergar el sujeto pensante en su entendimiento: "Esta misma idea es también muy clara y muy distinta, puesto que todo lo que de real y verdadero concibe clara y distintamente mi espíritu, y que contiene en sí alguna perfección, está totalmente contenido y encerrado en esta idea." ${ }^{25}$ Así, Dios pasa de ser un agente externo al sujeto, a formar parte de su conciencia, pues toda claridad y distinción, constituyente del criterio de verdad humano, está contenida en su idea.

De esta manera, tal idea se transforma en posibilitadora de la búsqueda epistemológica hecha por el hombre, pues todo conocimiento verdadero, toda certeza, se encuentra encerrada en la idea más perfecta, la cual está alojada al interior de la consciencia humana:

$\mathrm{Y}$ aunque pueda suceder que una idea dé origen a otra idea, esto, sin embargo, no puede continuar al infinito, sino que es necesario llegar por fin a una idea primera, cuya causa sea como un patrón o un original, en la que se halle contenida formal y efectivamente toda la realidad o perfección que se encuentra sólo objetivamente o por representación en estas ideas. ${ }^{26}$

La idea de Dios permite entonces, no sólo conocer la existencia de ese Ser, sino llegar al conocimiento de todas las cosas del mundo, dado que es el arquetipo de perfección, el modelo de sabiduría al cual el entendimiento humano se aproxima para poder llegar a la verdad. En este sentido, la noción de infinito, que contiene todo lo claro y distinto, es decir lo verdadero, deja al descubierto que el sujeto a pesar de su finitud puede acceder al conocimiento gracias a que esa noción está presente en su entendimiento y le sirve de prototipo de verdad. Aunque lo anterior evidencia los límites de la razón humana ante la infinitud, también revela que la idea de infinitud hace posible al sujeto el conocimiento de sí mismo y de todo cuanto existe, con lo cual el sujeto adquiere una total libertad epistémica.

\section{La importancia de Dios creador en la teoría del conocimiento cartesiana}

Como se mencionó, Descartes desde la Primera Meditación tiene la opinión de la existencia de un Dios todopoderoso y creador de su ser, pensamiento que en ese momento de su investigación debe suspender por falta de evidencias y que retoma en la Tercera Meditación. Antes de volver a abordar tal tema, su entendimiento lo había llevado a ser consciente de su existencia y al conocimiento del criterio de claridad y distinción, elementos que posibilitan someter a examen toda creencia, los cuales son avalados por Dios.

De esta manera cuando aparece nuevamente la idea de Dios, la existencia de este ser puede ser verificada racionalmente, llegando a la siguiente definición: "Bajo el nombre de Dios entiendo una sustancia infinita, eterna, inmutable, independiente, omnisciente, todopoderosa, y por la cual yo mismo y todas las demás cosas que existen (si es verdad que existen) han sido creadas y producidas."27

Las anteriores cualidades atribuidas a Dios, colocan en evidencia la diferencia ontológica que existe entre este Ser supremo y el sujeto 
pensante. Hay características que están en Dios, como la infinitud, la independencia, la omnisciencia, el poder y la perfección ${ }^{28}$ que por el contrario, en el hombre se dan como finitud, dependencia, e imperfección. ${ }^{29}$ Estas diferencias permiten elaborar los argumentos no sólo de la existencia de Dios, sino de la totalidad de la teoría del conocimiento cartesiana.

Sin embargo, consideramos que el principal rasgo de la preeminencia divina y uno de los más importantes para tal teoría, es la condición de Dios creador y conservador de la existencia del hombre, pues esa noción instaura inmediatamente una total dependencia de la criatura respecto a su creador; "de hecho, Descartes no considera la idea de que Dios pudiera no haberlo creado, pues ya está inscrito en la idea de Dios, que lo creó."'30

Es así que, al saber que todo tiene una causa, Descartes se da a la tarea de indagar sobre el origen de su existencia. Partiendo nuevamente de la posesión de la idea de Dios en su entendimiento, concluye que si él fuera el autor de su existencia jamás dudaría y no se habría privado de todas las perfecciones que dicha idea contiene. De lo que se sigue, que es absolutamente necesario que Dios sea el autor de su existencia y es más, que sea el que posibilite su conservación, es decir, que pueda permanecer existiendo cada instante de su vida:

En efecto, es una cosa muy clara y muy evidente (para todos aquellos que consideren con atención la naturaleza del tiempo) que para que una sustancia se conserve en todos los momentos que dura tiene necesidad del mismo poder y de la misma acción que serían necesarios para producirla y crearla completamente de nuevo si todavía no existiera. (...) Así, pues, aquí es preciso que me interrogue a mí mismo, para saber si poseo algún poder
0 alguna virtud que sea capaz de hacer de modo que yo, que existo ahora, exista también en el futuro: pues ya que no soy más que una cosa que piensa(...) si se encontrara en mí un poder tal, por cierto, debería, por lo menos, pensarlo y conocerlo; pero no experimento ninguno en mí, y de ahí conozco evidentemente que dependo de un ser diferente de mí. ${ }^{31}$

Por consiguiente, la existencia del hombre, incluyendo en ella su conservación, depende enteramente de Dios. Es ahora patente la importancia del planteamiento de la perfección, omnipotencia e infinitud de Dios, en comparación con la limitación humana, pues la creatura necesita permanentemente a su creador para seguir en la existencia. La diferencia sustancial entre Dios y el sujeto, siendo el primero una sustancia independiente y el segundo una sustancia creada, confirma aún más la dependencia de la creatura humana respecto a su creador. Pero no es solamente una dependencia ontológica, pues cuando Dios crea al hombre coloca en éste la idea de sí mismo, junto con la idea que tiene el hombre de su existencia, para que pueda conocer, por lo cual hay también una dependencia epistemológica. Así lo expresa Descartes, en el momento de la indagación sobre el origen de la idea de Dios:

Y por consiguiente, no queda más que decir sino que, al igual que la idea de mí mismo, (la idea de Dios) ha nacido conmigo a partir del momento en que he sido creado.

Y por cierto, no debe parecer extraño que Dios, al crearme, haya puesto en mí esa idea para que sea como la marca del artífice impresa en su obra, ni tampoco es necesario que esta marca sea algo diferente de esa misma obra. ${ }^{32}$

La idea de Dios se encuentra en el hombre de manera innata y le permite tener la garantía de que hay un conocimiento verdadero, al cual como sujeto pensante y capaz de

28. Aunque la perfección no aparece dentro de esta definición, es un rasgo definitivo en la comprobación de la existencia de Dios, como ya se mostró, en el primer argumento de la existencia de Dios.

29. La imperfección del hombre es evidente porque duda y puede equivocarse en sus juicios.

30. WILLIAMS, Bernard, El proyecto de la investigación pura, UNAM, Mexico, 1990, p. 150.

31 DESCARTES, René, Óp. cit., "Meditaciones Metafísicas", Tercera Meditación, p. 248, (ATIX, 39)

32. Ibíd., Tercera Meditación, p. 250, (ATIX, 41). 
realizar operaciones en el entendimiento tiene acceso. Por ello, no es carente de significación que Descartes haya escrito a Mersenne: "Ahora bien, estimo que todos aquellos a los que Dios ha dado el uso de esta razón están obligados a emplearla principalmente para tratar de conocerlo y conocerse a sí mismos".33 La razón es pues, un privilegio que le proporciona al sujeto la posibilidad epistemológica que otras criaturas no poseen.

Entonces, sería gracias a Dios, el cual quiso colocar las ideas innatas en el entendimiento del hombre en el momento de crearlo, que éste puede adquirir el conocimiento; desde el cogito, que lo hace consciente de sí mismo, hasta la existencia de Dios y a partir de allí, de todo cuanto existe en el mundo. En pocas palabras, es gracias a un Dios creador, el cual proporciona las características adecuadas en el sujeto creado, que éste puede emprender la ruta de indagación hacia la certeza.

Podemos agregar que, en cuanto al orden ontológico Dios es anterior al hombre pues es quien lo crea, y éste permanece siempre en total dependencia respecto a su creador. Sin embargo, en el orden epistemológico y de la investigación, el hombre es anterior a Dios, pues aunque la idea de Dios es la primera en cuanto contiene a las demás, según el método seguido por Descartes, la certeza de su existencia es encontrada antes que las evidencias racionales de la existencia de Dios; ello sucede así, porque el cogito es el punto arquimédico que permite hallar el criterio de verdad en el entendimiento del hombre, el cual posteriormente, Dios avala. Lo anterior permite confirmar que Dios creó al sujeto epistemológicamente libre, ya que puede acceder desde sí mismo al conocimiento usando sus facultades racionales y decidiendo qué afirmar o negar, de lo que halla en su entendimiento. Este rasgo es lo que asemeja al hombre con su creador:
(...) el libre albedrío es de suyo la cosa más noble que puede haber en nosotros, tanto que nos hace semejantes a Dios y parece eximirnos de estar sujetos a él y que, por consiguiente, su buen uso es el más grande de todos nuestros bienes, es también el más propiamente nuestro y el que más nos importa, de donde se sigue que sólo de él pueden provenir nuestros mayores contentos. ${ }^{34}$

Pero a pesar de haber llegado hasta el punto de encontrar un sujeto libre, con la facultad de conocer y de emprender desde sí mismo la ruta epistemológica, además, avalado por un Dios que existe realmente y que garantiza la certeza de sus hallazgos claros y distintos, hay todavía algo que no está resuelto, la posibilidad de que ese Ser pueda engañar al hombre en lo que parezca más evidente.

\section{La bondad de Dios como cimiento moral de la certeza}

El asunto que no deja alcanzar la máxima certeza, que hace tambalear hasta las verdades matemáticas, la posibilidad de un 'Dios engañador,' necesita ser clarificado para despejar por fin toda sombra de incertidumbre. Como vimos, cuando aparece la opinión de un Dios, que además de creador es todopoderoso, la veracidad del conocimiento más evidente hasta esa instancia, las verdades matemáticas, es puesta en duda. Un ser que ostenta un poder sin límites podría hacer que el hombre viviera engañado hasta en lo que su entendimiento le muestra como más evidente, tendría la capacidad para sumergirlo en el error y la falsedad del cual le sería imposible salir, dada su dependencia hacia ese Ser que lo creó. Sin embargo, queda el precedente de que tal vez Dios no lo engañaría pues es soberanamente bueno. ${ }^{35}$

Cuando esta hipótesis es retomada, Descartes se da a la tarea de demostrar la existencia de Dios, para posteriormente, verificar si es engañador. Es así que, luego de llevar a cabo esta demostración, el filósofo

33. DESCARTES, René, Óp. cit., Correspondencia, p. 353. (ATI, 144).

34. Ibid., p. 473, (AT, V, 85).

35. DESCARTES, René, Óp. Cit. "Meditaciones Metafísicas", Primera Meditación, p. 220, (AT IX, 16). 
francés utiliza el argumento basado en la perfección de Dios para despejar la duda respecto a la posibilidad del engaño divino. En tal argumento expone que aunque éste Ser posea un poder que le permite hacer cualquier cosa, incluso engañar al hombre, jamás lo haría, ya que querer engañar indica maliciayes unalimitación queva en contra del atributo de perfección, que es exclusividad divina. Así, la verdad del conocimiento humano es avalada por la soberana bondad de Dios, cualidad por la cual nunca querría que el hombre permaneciera en el engaño y el error:

Porque primeramente reconozco que es imposible que alguna vez/ me engañe, puesto que en todo fraude y engaño se encuentra cierto tipo de imperfección y aunque parezca que poder engañar sea señal de sutileza, 0 de poder, sin embargo, querer engañar atestigua sin duda debilidad o malicia. Y, por consiguiente, esto no puede encontrarse en Dios. ${ }^{36}$

Vemos cómo la libertad infinita que Dios posee, le permite decidir entre engañar al hombre o no hacerlo, en lo que se presenta al entendimiento de éste como claro y distinto; cuando decide no engañar, se manifiesta como un Ser moralmente perfecto pues no admite malicia. De esta manera, su bondad es posible gracias al ejercicio de su libertad. Así mismo, a partir de los argumentos que respaldan la demostración de la imposibilidad del engaño en Dios, encontramos que su perfección impide cualquier carencia o limitación, y el engaño es la ausencia de verdad y la demostración de malicia, por consiguiente, la soberana bondad de Dios aparece como atributo perteneciente a la condición de perfección de Dios y ligado al libre albedrío.

Ahora bien, con el aval de un Dios bueno se logra la absoluta confirmación de las verdades matemáticas, ${ }^{37}$ pues el sujeto sabe que lo que se presenta como claro y distinto a su entendimiento, efectivamente lo es. A partir de la comprobación de la existencia de Dios y de la erradicación de la posibilidad de que sea un engañador, por fin el hombre puede estar seguro de la verdad de su conocimiento, ya que la claridad y distinción a la que su entendimiento es capaz de llegar se encuentra respaldada por un Dios que nunca querría engañarlo y que le garantiza que es posible llegar hasta la certeza. Para confirmar la imposibilidad de que Dios sea engañador, Descartes señala en los Principios de la Filosofía:

El primer atributo de Dios que aquí se presenta a consideración consiste en que es sumamente veraz y fuente de toda luz; de tal modo que repugna en absoluto que nos engañe o que sea propia y positivamente causa de los errores a que estamos sujetos, según sabemos por experiencia. Pues aunque el poder engañar parece entre nosotros, los hombres, una señal de ingenio, sin embargo, la voluntad de engañar surge siempre sólo de la malicia, 0 del miedo, 0 de la debilidad $y$, por consiguiente, nunca puede ser atribuida a Dios. ${ }^{38}$

Precisamente tanto repugna a Dios el engaño, que le otorgó a su criatura la capacidad y la libertad de llegar desde sí mismo al conocimiento, para lo cual es necesario refinar el trabajo del entendimiento y asentir únicamente lo que aparezca ante éste como claro y distinto, para no equivocarse en los juicios emitidos. El papel de la voluntad en el hombre es por ello fundamental, ya que ésta es la que le permite optar por la verdad, la que afirma o niega según sea el caso, lo que el entendimiento le muestra. De ahí la gran responsabilidad de la voluntad, pues hacer afirmaciones sin el suficiente trabajo de inspección de las ideas puede acarrear la caída en la falsedad.

37. Hay que recordar que las verdades matemáticas son también creación de Dios: "Así, no hay por qué pensar que las verdades eternas dependen del entendimiento humano, o de la existencia de las cosas, sino tan sólo de la voluntad de Dios que, como supremo legislador, las ha ordenado desde toda la eternidad". DESCARTES René, Op. cit., Meditaciones Metafísicas con Objeciones y Respuestas, Respuestas a las Sextas Objeciones, p. 333.

38. DESCARTES, René, Los Principios de la filosofía, en: Obras Escogidas, Trad: Ezequiel de Olaso, Charcas, Buenos Aires, 1980, a. 29, p. $324(A T I X, B, 16)$. 
Pero, a pesar de la soberana bondad de Dios, es un hecho que el sujeto a veces se equivoca. Si Dios por ser bueno no engaña, como está claro, la aparición del error en el conocimiento del hombre demuestra que tal error es causado por él mismo, al no seguir el proceso epistemológico correctamente, y emitir juicios a la ligera, con lo cual Dios queda excluido de cualquier responsabilidad a este respecto.

De manera que, la concepción de un 'Dios bueno' que es algo cierto para la escolástica, lo es también para Descartes, pues él resalta la misma noción de bondad divina como atributo de la perfección de un Ser supremo, y la coloca como respaldo a su veracidad. Esto hace que el filósofo francés permanezca aún ligado a creencias de la tradición escolástica; sin embargo, ello no le resta originalidad a su pensamiento, pues como hemos visto, la ruta de indagación epistémica que parte del sujeto pensante y encuentra a Dios en el camino para avalar el conocimiento, hace patente la libertad de Dios y la libertad del hombre en el proceso de adquisición del conocimiento, concepción distante de la aceptada por la tradición. Así mismo, la consideración de un Dios bueno demuestra que la voluntad, o libertad de Dios, es todopoderosa e infinita, y hace posible una bondad igualmente infinita, que se convierte en la garantía de la veracidad de todo conocimiento claro y distinto que halle el sujeto pensante. Así es como la perfección moral de Dios se convierte en pilar de la teoría epistemológica cartesiana.

En cuanto a la relación de dependencia e independencia del hombre hacia Dios, podemos afirmar que como creatura es natural que el hombre siempre dependa de su creador, pues éste no sólo lo crea sino que lo mantiene en la existencia; además, depende epistemológicamente, en cuanto su creador le brinda las facultades racionales y los elementos, como las ideas innatas, para que le sea posible llegar a conocer, y de manera cierta.

Sin embargo, al otorgarle la posibilidad de ir en búsqueda del conocimiento desde sí mismo, de cuestionar todo aquello de lo que no tenga evidencias racionales y de abstenerse de emitir juicio debido a la carencia de certidumbre respecto a lo que se presenta en su entendimiento, el sujeto es un ser libre. Es creado libre para conducir su búsqueda hacia el conocimiento cierto, lo cual también le otorga la responsabilidad de llevar a cabo el proceso epistemológico de manera correcta, atendiendo al criterio de verdad. Por esto, no todas las creaturas racionales llegan a la verdad, no por carecer de facultades para ello, sino porque la mayoría de los hombres no están en disposición de abandonar sus prejuicios, los argumentos de autoridad y de asumir la responsabilidad que implica hacerse cargo de buscar, por sus propios medios, la certeza.

\section{Conclusiones}

La teoría del conocimiento planteada por Descartes es innovadora en su método, en cuanto propone una nueva ruta epistemológica que parte del sujeto pensante, de su capacidad racional, que lo lleva de la certeza de sí mismo a la certeza de Dios y luego a la del mundo, con lo cual inaugura el pensamiento centrado en el sujeto. Así mismo, otorga al hombre total libertad en la indagación de la verdad, brindándole la posibilidad de buscar la certeza, detener el juicio ante la incertidumbre, y asentir únicamente lo debidamente respaldado por el criterio de verdad. Esta libertad también le permite al hombre tomar distancia de los argumentos de autoridad y separar los asuntos de fe de la investigación epistémica.

De otro lado, Dios se presenta como un Ser infinitamente libre, pues aparte de querer

39. Santo Tomás afirma en su Suma Teológica: "(...) se concluye que sólo Dios tiene por esencia todo tipo de perfección. Así, es el único bueno por esencia. (...) es absolutamente cierto que, tal como dijimos ( 9.2 a. 3) y en eso se concuerda con Aristóteles, lo primero es aquello que es ser y bueno por esencia; y nosotros le llamamos Dios" AQUINO, Tomás de, Suma de Teología, La Editorial Católica, Madrid, 1998, P. I, q. 6, a. 2 y 4, pp. 136-138. 
crear al hombre con capacidad para llegar al conocimiento cierto al otorgarle el criterio de claridad y distinción, él mismo decide avalar tal criterio de verdad. Igualmente, cuando Dios pudiendo hacer cualquier cosa, toma la decisión de no engañar al sujeto en los hallazgos de su razón, hace uso de su libertad infinita, la cual permite la manifestación de su bondad.

Ahora bien, las razones de fondo que aparecen respaldando la teoría cartesiana del conocimiento están ancladas en la concepción tradicional de Dios, que lo presenta como creador del hombre y como un Ser infinitamente bueno, nociones ampliamente reconocidas como creencias religiosas. Específicamente la soberana bondad de Dios, atributo que soluciona los problemas de veracidad del conocimiento surgidos por la hipótesis del Dios engañador, y que revela la infinita libertad divina, es uno de los elementos de convergencia más notorio entre la escolástica y el cartesianismo. Este rasgo de Dios se convierte en la piedra angular del edificio epistemológico construido por Descartes, lo cual conlleva a que una categoría moral se convierta en la encargada de proporcionar una certeza epistemológica.

Sin embargo, el pensamiento cartesiano no es una simple acomodación de ideas innovadoras en la escolástica, pues su visión sobre Dios fuente de los tesoros de la ciencia y del sujeto como punto de partida epistemológico, hizo posible la transformación de estas nociones en torno al conocimiento, dando lugar al racionalismo, que por ejemplo en Spinoza, se radicaliza. La convergencia de elementos innovadores y tradicionales al interior de esta teoría del conocimiento, hacen del pensamiento cartesiano un terreno de encuentro entre la mentalidad de la Edad Media y de la Modernidad. Por eso, es característico de la posición histórica de Descartes el que, al paso que plantea una nueva pregunta y sus primeras certezas se encuentran de una manera nueva en la conciencia del sujeto, la culminación de la tarea depende, esencialmente para él, de las concepciones tradicionales de Dios. ${ }^{40}$

Así mismo, la anterior combinación de elementos en el sistema expuesto por Descartes, explica por qué en muchas ocasiones es complejo comprender a fondo su pensamiento y por qué ha dado lugar a tantos debates entre opositores y defensores de su teoría, a lo largo de cuatrocientos años. 


\section{Bibliografía consultada:}

AQUINO, Tomás de, Suma de Teología, La Editorial Católica, Madrid, 1998.

DESCARTES, René, Meditaciones metafísicas con objeciones y respuestas, Trad:Vidal Peña, Alfaguara, 1977.

DESCARTES, René, Meditaciones metafísicas y otros textos. Trad: E. López y M. Graña, Gredos, Madrid, 1987.

DESCARTES, René, Obras escogidas. Trad: Ezequiel de Olaso, Charcas, Buenos Aíres, 1980.

DESCARTES, R., LEIBNIZ, G., Sobre los Principios de la Filosofía. Trad: E. LÓPEZ y M. GRAÑA, Gredos, Madrid, 1989.

FAJARDO, José del Rey, MARQUÍNEZ, Germán, Denis Mesland Amigo de Descartes y Maestro Javeriano, Pontificia Universidad Javeriana, Bogotá, 2002.

SERRANO, Gonzalo, "¿Qué nos importa Descartes todavía?" En: Memorias del seminario en conmemoración de los 400 años del nacimiento de René Descartes, Academia Colombiana de Ciencias Exactas, Físicas y Naturales, Bogotá, 1997.

WILLIAMS, Bernard, El proyecto de la investigación pura, UNAM, México, 1995.

WILSON, Margaret, Descartes, Trad: José A. Robles, UNAM, México, 1990. 